\title{
Infrastructure Watch Culture: Zambia's Infrastructure Report Card
}

\author{
Mundia Muya ${ }^{1, *}$, Chisanga Kaluba ${ }^{1}$, Ian Nzali Banda ${ }^{1}$, Suzanne Rattray ${ }^{2}$, Christopher Mubemba $^{3}$, \\ Garry Mukelabai ${ }^{4}$ \\ ${ }^{1}$ Department of Civil and Environmental Engineering, the University of Zambia, Zambia \\ ${ }^{2}$ Rankin Engineering Consultants, Zambia \\ ${ }^{3}$ Department of Electrical and Electronic Engineering, the University of Zambia, Zambia \\ ${ }^{4}$ Support Services Department, Zambia Information and Communications Technology Authority, Zambia
}

Copyright $\mathrm{C} 2017$ by authors, all rights reserved. Authors agree that this article remains permanently open access under the terms of the Creative Commons Attribution License 4.0 International License

\begin{abstract}
Every country needs a well-maintained public infrastructure system to deliver essential services to its citizens and propel economic growth. The Engineering Institution of Zambia carried out a comprehensive study on the state of public infrastructure in Zambia and produced the country's first ever 'report card'. A team of experts assessed the state of infrastructure based on four criteria: condition; capacity; operations; and security. The purpose of the report card was to sensitize the government and the general public about the condition and performance of engineering infrastructure in the country. The report covered seven categories comprising: roads and bridges; water supply, sanitation and solid waste; electricity; information and communication technology; and airports and railway infrastructure. These were graded on a scale A to $\mathrm{F}$ where Grade $\mathrm{A}$ was awarded to infrastructure that was adequate for present and future use and $\mathrm{F}$ to that which was totally inadequate. Overall, the infrastructure system was found to be inadequate to meet present and future needs in a number of aspects.
\end{abstract}

Keywords Infrastructure, Condition, Operations, Capacity and Security

\section{Introduction}

Infrastructure is the bedrock of any country's economic and social well-being. A world-class infrastructure system that consistently performs efficiently is a must for any economy to be competitive [1]. Infrastructure must be well operated and maintained if the social and economic growth of any country is not to be impeded. Zambia has reached a pivotal moment with regard to implementation, maintenance, and rehabilitation of public infrastructure. Most of the infrastructure comprising roads, bridges, railway lines, airports, power generation, power transmission systems, power distribution, water supply and sewerage networks were constructed about forty years ago and currently are in relatively poor working condition as evidenced by the many shortcomings in the required levels of service delivery [2]. For example, the country has been experiencing national power outages and daily power cuts in the past few years [3], and several towns have also been experiencing erratic water supply [4]. To further exacerbate this situation, rapid rural-urban migration has also been on the rise. As a result, the Zambian government is faced not only with the problems of rehabilitation but also increased demand for infrastructure expansion [4]. Despite these and other reported failures of infrastructure service delivery, there has been to date no systematic study to establish the performance of the country's infrastructure at national level [5]. Previously, there has been no systematic national reporting framework on the state of infrastructure.

The importance of Zambia having a reliable and accurate reporting framework that depicts the condition and performance of key infrastructure cannot be over-emphasized if the country is to achieve its development agenda and improve the well-being of citizens. It is against this background that the Engineering Institution of Zambia (EIZ) embarked on the production of the first ever infrastructure report card (IRC) for Zambia. This entailed an assessment of the condition and serviceability of the existing infrastructure. The infrastructure categories that were assessed were:

- roads and bridges;

- water supply, sanitation and solid waste;

- electricity;

- information and communication technology; and

- airports and railway lines.

The IRC was produced in order to provide the baseline state of the existing infrastructure; it's capability to meet present and future needs; and required level of service. It was 
envisioned that the IRC would help decision-makers in government and other stakeholders, both public and private to make informed decisions with regard to infrastructure development in the various categories that were assessed. Initially, EIZ produced an IRC framework [6], which outlined the methodology to be used to produce the IRC.

\section{IRC Concept}

An IRC normally consists of two parts: a concise Infrastructure Scorecard and a detailed report. The Scorecard simply presents the grades which indicate the quality or performance of infrastructure in a country. Each infrastructure category is given a grading based on its performance. The implication and meaning of the grading is explained. Individual grades for each infrastructure category for different parts of the country are then aggregated to give an overall grade for the entire country. The detailed report on the other hand gives a full account of what factors were considered during the assessment. It includes a detailed description of the infrastructure system and the grading of each component of the infrastructure category that was assessed.

The American Society of Civil Engineers (ASCE) and the Institution of Civil Engineers (ICE) of the United Kingdom (UK) were among the first to develop report cards in the late 1990s. Similar report cards have been developed in Canada, Australia and South Africa. Several methodologies have been used to rate infrastructure and issue infrastructure report card grades.

\subsection{The ASCE IRC Methodology}

In the United States of America, regional infrastructure report cards have been produced following the model used by the American Society of Civil Engineers (ASCE). The Los Angeles Infrastructure Report Card (2003) and Portage, Stark and Summit Infrastructure Report (2005) rated infrastructure based on consideration of three fundamental components of infrastructure: condition, capacity and operations which were each given equal weighting in the assessment. However, some other regional report cards included a fourth component, security. The California Infrastructure Report Card (2005) is one such report. It is most likely that security was not included in the other two reports because the information needed to accurately assess its status was not readily available to engineering professionals at the time the reports were generated. With each infrastructure category, a performance indicator was identified for each fundamental component. A rating criterion was then applied to each performance indicator to produce letter grades, based on the ASCE National Report Card's approach, which has the following scale:

$\mathrm{A}=90-100 \%$;

$\mathrm{B}=80-89 \%$;
$\mathrm{C}=70-79 \%$; and

$\mathrm{D}=41-69 \%$.

Report card grades were determined based on the percentage of the infrastructure that met the stated criteria. For example, if $77 \%$ of the roads were in good condition or better, that would earn a grade of $\mathrm{C}$ for the condition fundamental component. Similarly, a grade was issued to other fundamental components and the resulting overall grade for each category of infrastructure was an average of the individual grades of all the fundamental components. In addition, an overall grade accounting for the entire infrastructure category was issued by evaluating the average grade from the individual infrastructure grades [2].

Unlike performance indicators, the fundamental components were not infrastructure specific. Three fundamental components which were normally considered in the assessment were:

- Capacity - Here the assessment sought to determine whether the current infrastructure would be able to support the current population as well as the projected population growth in ten years time. The existing capital improvements programs were key factors in the capacity assessment;

- Operations - The key factors considered were the infrastructure system compliance with the existing regulatory requirements and the sufficiency of the current funding levels for infrastructure maintenance; and

- Security - The elements addressed included those physical improvements required to assure asset protection from identifiable threats to the category of infrastructure considered.

\subsection{Engineers Australia IRC Methodology}

In the New South Wales (NSW) Infrastructure Report Card (2003) and Queens Land (QLD) Infrastructure Report Cards (2004), Engineers Australia (EA) rated infrastructure on consideration of five fundamental components: asset condition; asset availability and reliability; asset management; sustainability (including economic, environmental and social issues); and security [2].

In arriving at a grade, the concepts of "level of service" and "fitness for purpose" were defined for each infrastructure sector. Performance indicators were identified for each fundamental component and the rating was determined based on these parameters. Each fundamental component was given a grade and the overall grade for the infrastructure system was an average of all the individual grades for each fundamental component. The report cards produced by EA do not specify that infrastructure was graded based on the percentage of the infrastructure that met the stated criteria. They only state that an infrastructure system is awarded a grade on a scale A to F where Grade A was for an infrastructure that is adequate for present and future use and $\mathrm{F}$ to that which was totally inadequate [2]. 


\subsection{ICE Infrastructure Report Card Methodology}

The State of the Nation Report is prepared each year by the Institution of Civil Engineers (ICE) in the UK. In the State of the Nation Report Card (2003) and the Wales Report Card (2004), the grading given to each category was an assessment of its performance over the previous 12 months. In addition, each category was also given a grading for sustainability, which was a measure of how well the infrastructure was meeting present needs without compromising those of the future [2].

Fundamental components and performance indicators used to grade the infrastructure were not stated in the report. Perhaps this was because the report was targeted at a wide audience of stakeholders, including politicians, civil servants, regulatory bodies and the media. The report did, however, state that the grading system used and its interpretation were based on the ICE infrastructure grading system based on scale of grades from A to E, where Grade A was for infrastructure with "Good" performance and Grade E with "Bad" performance [2].

\subsection{The South African Institution of Civil Engineers (SAICE) IRC Methodology}

SAICE graded each category of infrastructure based on condition and performance, and capacity versus need. Like the report card produced by ICE, the SAICE Report Cards (2006 and 2011) did not state the performance indicators used to grade the infrastructure. This makes it difficult to make detailed comparisons of the report card methodologies used by both SAICE and ICE. However, closer inspection of factors highlighted in the report cards reveals that similar performance indicators were being used like those by ASCE and EA. From the ASCE and EA report card methodologies, one can note that the infrastructure was basically graded based on condition, capacity, operations and maintenance and security versus need [2].

\subsection{The Canadian Municipal IRC Methodology}

The Canadian Municipal Infrastructure Report Card is produced by a collaboration of the Canadian Society for Civil Engineers, the Federation of Canadian Municipalities, the Canadian Construction Association, and the Canadian Public Works Association. The infrastructure is graded based on information collected from a web based survey of all senior representatives of all municipalities in Canada.

The survey includes questions relating to the condition and capacity of the infrastructure. The survey asks each municipality to report on the percentage of their systems that are in very poor, poor, fair, good or excellent condition. A rating is then assigned to each asset group based on the percentages that were in very poor to excellent condition. It is important to note that letter grades are not used to report the condition of the infrastructure but just statements ranging from very poor to excellent as listed previously.
Furthermore, the information on condition was the only data that was used to determine the overall ratings. The information from the survey relating to capacity was summarized and used in the general discussion of the state of asset management systems in municipalities [7].

\section{The EIZ IRC Framework}

From the IRC's that were reviewed, three fundamental components of infrastructure are normally used to assess infrastructure. These include condition, capacity and management systems [6].

The EIZ IRC framework [6] also accounted for similar fundamental components. These included: condition; capacity; operation; and security. Condition referred to the physical state of the infrastructure to provide for the required levels of service. Capacity referred to the ability of the infrastructure system to meet demand. Operation took into account facility management and maintenance. The security component of the assessments considered measures put in place to protect the infrastructure against acts of sabotage and vandalism.

In the IRC framework [6], a performance indicator was identified for each infrastructure category. These indicators were used to assess each fundamental component of infrastructure. For example, in order to assess the condition component of roads, the residual pavement life was one performance indicator that was used, while for railways, the physical condition of the track was used. Appendix shows the performance indicators used for road, rail and airport infrastructure respectively. Thus, fundamental components were not infrastructure specific, while the performance indicators were infrastructure specific. Each of the fundamental components was given an equal weight of 25 percent, amounting to a total of 100 percent as was prescribed in the EIZ IRC framework. The grading for each of the different categories was determined by information gathered from a desk study of annual reports, interviews with infrastructure experts and sample field studies. A grade was then issued for each fundamental component based on the infrastructure grading system given in the EIZ IRC framework.

\subsection{Implementation of EIZ IRC Framework}

The grading for each of the different categories of infrastructure was determined by information that was gathered from desk and field studies. The desk study reviewed reports produced by infrastructure management government departments and other institutions as well as other publicly accessible documents with information relating to the state and performance of infrastructure. The field studies consisted of sample investigations of the infrastructure as well as interviews with technical experts involved in the management of the infrastructure.

In order to ensure that the grading of the infrastructure was repeatable and comparable with future assessments, an 
effort was made to quantify each component of the assessment. For example, for airport infrastructure, each airport was graded separately and a weighted average was used to come up with the national grade. Additionally, for each airport, an effort was made to quantify each component of the assessment. One example of how one airport was graded is shown in Table 1 below. The condition component for each airport was divided into six sub-components and these included: runway, terminal facilities, concourse, hangars, cargo facilities and communication. The weighting of each sub-component was based on how critical that sub-component was to the functioning of the airport and the cost for the maintenance and expansion of that sub-component. The runway accounted for 40 percent of the condition component of the airport, while the terminal facilities accounted for 25 percent. For this particular airport, the score of 41 percent for the runway condition was arrived at after considering a number of factors related to the performance indicators given in Table 5 of the EIZ IRC Framework (see Appendix). The runway had exceeded its pavement residual life; runway approach lights had been vandalized and some runway markings required repainting [5]. This particular runway required critical rehabilitation for it to be fit for present and future use. Reference was then made to the EIZ IRC framework which stated that if infrastructure requires critical rehabilitation then it should be given a rating of between 41 to 69 percent depending on how much work was required to bring it to acceptable level of service (See Appendix). For the fundamental component of capacity, the runway had a weight of 60 percent, while terminal facilities had a weight of 40 percent. Again, these weights were based on how critical the sub-component was to the functioning of the airport. The 79 percent score for the capacity of the runway was arrived at after considering factors related to the performance indicators given in Table 5 of the EIZ IRC Framework. The runway was able to meet peak demand for aircraft landings and take-offs. However, taking-off and landing of aircrafts was one at a time and the maximum size of aircraft that could be accommodated was DC 10 or planes of similar specifications. Further, the runway overrun distance was $800 \mathrm{~m}$, meaning that it was less than the required $1 \mathrm{~km}$. Major rehabilitation works were required to address these issues and based on the EIZ IRC framework Table 1 a score of 79 percent was awarded. The terminal facilities were not able to meet peak demand. In particular, the departure lounges were not able to cope with demand at peak hours and outbound passengers were forced to stand due to insufficient sitting space. The office space for employees working in the terminal building was also not adequate. There were no conveyor belts, lifts, or escalators at the terminal building. Critical rehabilitation works were required to improve the handling capability of terminal facilities and thus from Table 1 of the EIZ Framework a percentage of $55 \%$ was awarded to terminal facilities for capacity [5].

A similar approach was used to grade the other sub-components for the condition component and an average of 43 percent was calculated. The other three fundamental components were also similarly graded. Finally, the infrastructure category grade was calculated by weighing each fundamental component at 25 percent. The national grade was an aggregate of the individual airport grades as shown in Table 2.

Table 1. Grading for SMKIA

\begin{tabular}{|c|c|c|c|c|c|c|}
\hline \multicolumn{3}{|c|}{ Condition Component } & \multicolumn{2}{|c|}{ Capacity Component } & \multirow{2}{*}{$\begin{array}{c}\text { Operations Component } \\
\text { Score } \%\end{array}$} & \multirow{2}{*}{$\begin{array}{c}\text { Security Component } \\
\text { Score } \%\end{array}$} \\
\hline & Score \% & Weight \% & Score \% & Weight \% & & \\
\hline Runway & 41 & 40 & 79 & 60 & \multirow{6}{*}{50} & \multirow{6}{*}{70} \\
\hline Terminal & 41 & 25 & \multirow{5}{*}{55} & \multirow{5}{*}{40} & & \\
\hline Concourse & $\mathbf{0}$ & 5 & & & & \\
\hline Hangars & 78 & 10 & & & & \\
\hline Cargo & 41 & 10 & & & & \\
\hline Communication & 41 & 10 & & & & \\
\hline $\begin{array}{c}\text { Average Component } \\
\text { Score }\end{array}$ & 43 & & 69 & & 50 & 70 \\
\hline $\begin{array}{c}\text { Average Component } \\
\text { Grade }\end{array}$ & $F$ & & $D$ & & $D$ & C \\
\hline \multirow[b]{2}{*}{$\begin{array}{l}\text { Average Airport } \\
\text { Grade at } 25 \% \text { for } \\
\text { Each Component }\end{array}$} & Score & Grade & Interpretation & \multicolumn{3}{|c|}{ Condition description } \\
\hline & 58 & $\mathrm{D}$ & Poor & \multicolumn{3}{|c|}{$\begin{array}{c}\text { Critical rehabilitation required in one or more of the infrastructure } \\
\text { condition, committed investment, regulatory regime and planning } \\
\text { processes to enable infrastructure to be fit for its present and future } \\
\text { use }\end{array}$} \\
\hline
\end{tabular}

SMKIA stands for Simon Mwansa Kapwepwe International Airport 
Table 2. International Airport National Grade

\begin{tabular}{|c|c|c|c|c|c|c|c|c|c|c|}
\hline Airport & $\begin{array}{c}\text { Condition } \\
\text { Score } \\
\& \\
\text { Grade }\end{array}$ & \multicolumn{2}{c|}{$\begin{array}{c}\text { Capacity Score } \\
\text { \& Grade }\end{array}$} & \multicolumn{2}{c|}{$\begin{array}{c}\text { Operations \& Score } \\
\text { Grade }\end{array}$} & \multicolumn{2}{c|}{$\begin{array}{c}\text { Security Score } \\
\text { \& Grade }\end{array}$} & \multicolumn{2}{c|}{ Overall Score \& Grade } \\
\hline KKIA & 75 & $\mathrm{C}$ & 80 & $\mathrm{~B}$ & 70 & $\mathrm{C}$ & 90 & $\mathrm{~B}$ & 79 & $\mathrm{C}$ \\
\hline HMNIA & 60 & $\mathrm{C}$ & 74 & $\mathrm{C}$ & 80 & $\mathrm{~B}$ & 80 & $\mathrm{~B}$ & 74 & $\mathrm{C}$ \\
\hline SMKIA & 43 & $\mathrm{D}$ & 69 & $\mathrm{D}$ & 50 & $\mathrm{D}$ & 70 & $\mathrm{C}$ & 58 & $\mathrm{D}$ \\
\hline MFIA & 38 & $\mathrm{~F}$ & 74 & $\mathrm{C}$ & 50 & $\mathrm{D}$ & 70 & $\mathrm{C}$ & 58 & $\mathrm{D}$ \\
\hline \multicolumn{8}{|c|}{ International Airport National Grade } & & 67 & $\mathrm{D}$ \\
\hline
\end{tabular}

KKIA stands for Kenneth Kaunda International Airport

HMNIA stands for Harry Mwaanga Nkumbula International Airport

MFIA stands for Mfuwe International Airport

The EIZ Framework was designed as a rating system to be applied across different infrastructure categories so that there can be a common basis for comparing the performance of different infrastructure sectors. Taking another example of rail infrastructure, a summary of the rating of the two major rail networks in Zambia is shown in Table 3 below.

Table 3. Overall rating of rail infrastructure

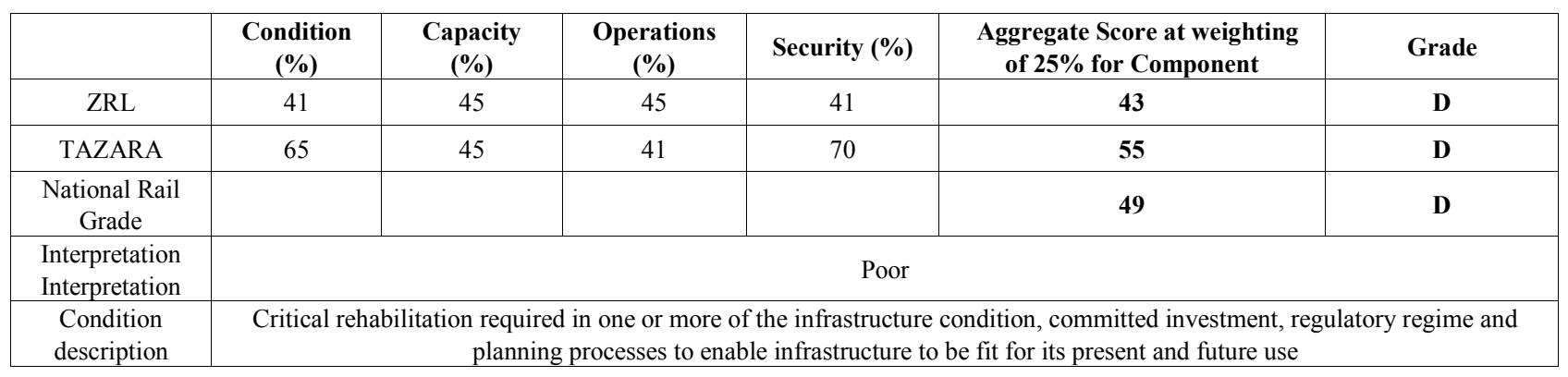

The condition ratings that are shown in Table 3 above were arrived at for each fundamental component of the rail infrastructure with reference to the performance indicators given in Table 4 and the rating criteria given in Table 1 of the EIZ IRC Framework (see Appendix). For the Zambia Railways limited (ZRL) rail network, the track quality was poor, forcing freight and passenger trains to move at average speeds of $20 \mathrm{Km} / \mathrm{hr}$ on some sections. Only 14 percent of the $848 \mathrm{~km}$ mainline met international standards of continuous welded rails with permissible speeds of $80 \mathrm{~km} / \mathrm{hr}$, while the rest of the track consisted of jointed rail. The communication and signaling systems were also in a poor state. The rolling stock equipment was in a deplorable state and could not fully support the transportation of both freight and passengers in a sustainable manner. Critical rehabilitation was required to enable the infrastructure to be fit for its present and future use. Thus from Table 1 of the EIZ Framework, a percentage of 41 was awarded for the condition state of the rail network. The other fundamental components were similarly graded.

\subsection{Further Development of EIZ IRC Framework}

While the EIZ IRC Framework attempts to quantify the assessment of the infrastructure so that the results are reproducible, the discretion of the experts carrying out the assessment still plays a role in the assessment. This makes it difficult to reproduce the results of the assessment for comparisons with future assessments. This is because most of the information used in the assessment is qualitative in nature. Further, the infrastructure grading system given in Table 1 of the IRC framework is not related to a specific numerical value. It remains to the discretion of the assessment expert to determine what specific percentage to assign for infrastructure requiring critical rehabilitation, just to give one example. In addition, no specific guidelines are given to define what is meant by critical or major rehabilitation. However, it is important to note that the assessment expert arrives at a specific grading in consultation with infrastructure experts managing a particular infrastructure sector.

An alternative method would be to use the rating methodology similar to the one used in the Canadian Municipal IRC, with the addition that only specific numerical values relating to the performance indicators be reported for each fundamental component. As an example for airport runway condition, the specific values of residual pavement life can be related to a specific fraction of the $25 \%$ value for the condition fundamental component.

\section{EIZ's 2014 Baseline Report Card for Zambia's Infrastructure}

In May 2015, EIZ produced an IRC for Zambia, making it the second country in Africa, after South Africa, to produce an Infrastructure Report Card. An overall national grade was not given as this would conceal variations in the 
grading of individual infrastructure categories. Thus, only infrastructure grades per category were produced. The findings of the assessment of the infrastructure were presented in an IS [8] and the details of the factors taken into consideration were presented in another detailed report [5]. The IS provided a summarized overview of the performance and quality of infrastructure in a simple $\mathbf{A}$ to $\mathbf{F}$ grade format, where $\mathbf{A}$ designates infrastructure that is adequate for current and future needs and $\mathbf{F}$ for failed infrastructure.

\subsection{Roads}

The road sector assessment revealed that only 40 per cent of the core road network was in maintainable condition and 60 percent required critical rehabilitation. Increased traffic volumes coupled with delayed maintenance due to insufficient funding led to the deterioration of the core road network condition. Funding for maintenance of the existing road stock continued to be under severe pressure with not more than 22 percent being received from budgetary allocation in the period 2012 to 2014 [9]. Consideration of poor funding and other factors outlined in the detailed report led to the award of a grade of $\mathbf{D}$ for roads.

For the core road network to be in maintainable condition, it was recommended that the maintenance of the existing road stock must be prioritized, with guaranteed annual funding released in a timely manner. Furthermore, a comprehensive feeder road rehabilitation programme was recommended for implementation, targeting at least 2000 $\mathrm{km}$ each year.

\subsection{Bridges}

Bridge infrastructure assessment showed that more than half of the stock was performing satisfactorily. However, about 41 percent required intervention to bring it to a satisfactory condition. This situation was not helped by the fact that only an average of around 60 percent of the budgeted amounts were being made available for bridge maintenance and rehabilitation. There was also a shortage of trained staff necessary for routine operations such as bridge inspections [10]. Bridge infrastructure was awarded a grade of $\mathbf{C}$, implying that the performance and quality of this infrastructure type was fair.

Increased training of staff was required in routine operations such as inspections and maintenance works in order to bring all bridges to satisfactory conditions. Adequate funding was required for effective bridge maintenance and management.

\subsection{Water Supply, Sanitation and Solid Waste}

This sector was sub-divided into four (4) distinct sub-sectors as each is driven by unique dynamics. Collapsing them into one component would have distorted the findings. Urban Water Supply

The assessment of this sub-sector was a grade of $\mathbf{D}$, meaning that the performance and quality of the infrastructure category was poor. In particular, the water supply networks were in dire need of refurbishment to reduce water losses, which would in turn reduce the levels of non-revenue water that at the time averaged around 48 percent. Extensive expansion of the networks and related infrastructure was required to increase coverage levels that at the time of the assessment ranged from 14 to 65 percent [11].

Capital investment for network expansion and general refurbishment was the single major requisite that needed to be urgently implemented to improve the condition and performance of this infrastructure sector. A further recommendation was that water loss in the network should first be reduced before network expansion.

\section{Urban Sanitation}

The assessment of this sub-category was $\mathbf{F}$, since the infrastructure was totally inadequate for present and future use. The infrastructure operated by the vast majority of commercial utilities was in poor state and needed rehabilitation. The coverage of the urban sanitation network was quite low in many jurisdictions with the exception of Copperbelt and Lusaka regions, which were the most urbanized provinces. Even in these provinces, newly established residential and peri-urban areas were not serviced due to limited capacity in the networks [12]. Thus, it was recommended that tariffs should eventually incorporate a surcharge for capital expenditure for sewerage expansion. Low levels of capital expenditure for sewerage maintenance had led to the deterioration of the network. In order for utility companies to raise additional funds aside from tariffs, sewage should be viewed not just as waste but also as a resource. Sewage waste can be used to produce fertilizer and methane gas, for example.

\section{Solid Waste Management}

The effective management of solid waste in Zambia has over the year's undergone continual deterioration largely due to the inability of local authorities to fulfil their delegated responsibility and cope with ever-increasing demand levels for these services. Several reasons can be cited for this service shortfall, including inadequate capital, low cost recovery for services rendered, coupled with ever increasing urbanization rates evidenced by the rapid growth of unplanned settlements.

In the vast majority of districts in Zambia, there were no discernible solid waste collection services. This posed a serious threat to public health and the environment. At the time of the study, only the City of Lusaka in the whole country had an engineered landfill site that, however, catered for only 25 per cent of the total waste generated in the city. All other towns disposed the generated solid waste at poorly managed dump sites that posed serious health hazard to the communities located in close proximity. These dump sites were inadequate in terms of overall capacity [12]. This infrastructure category was found to be totally inadequate for present and future use and was therefore awarded grade $\mathbf{F}$.

Rural Water Supply 
At the time of the assessment, only 67 percent of the rural population had access to water points that met the prescribed standards for safe water. The assessed grade for this sub-sector was $\mathbf{C}$ as the quality and performance were found to be generally fair. Sanitation infrastructure for rural areas was not considered, as the key role of the government in this sub-sector had been principally to create awareness among the communities on the importance of good hygienic practices and on how to construct well-functioning pit latrines for use at household level [11]. Therefore, capacity building of beneficiary communities to participate in the operation and management of the infrastructure is imperative to assure sustainability for rural water services. Furthermore, technology choices should at all times be simple to use but robust and easily maintainable by communities themselves to assure sustainability of the services.

\subsection{Electricity}

The electricity infrastructure system was found to be in immediate and urgent need for major rehabilitation and expansion. The generation part of the system needed consistent and regular expansion over the next five to ten years. To this end, the major power stations, Kariba North and Victoria Falls had been rehabilitated to design condition levels. However, the facilities at small hydropower stations had become obsolete and maintenance was increasingly difficult [13]. A rehabilitation program was, at the time of the study, underway to upgrade the small hydropower stations. The two major dams at both Kafue Gorge and Kariba North Bank were in need of urgent interventions.

The condition of the transmission system was good. However, the system was reaching the limits for which it was designed and this would soon begin to affect its performance. Therefore, there was need for expansion through the construction of new transmission lines and substations.

The greater challenge was in the distribution system, which was already not performing at the desired levels due to the increase in the number of customers without a commensurate increase in the distribution substations and lines. Most parts of the distribution system were old and obsolete and in need of immediate replacement. The system was in urgent need of voltage and capacity rehabilitation, expansion and upgrading. Vandalism of infrastructure facilities via thefts of steel, conductors, and oil was also very high [13].

From the surveys and reviews carried out for the generation, transmission and distribution plant, it was clear that some parts of the Zambian electrical power system was old and obsolete and in urgent need of upgrading or replacement. The overall assessed grade for electricity infrastructure was $\mathbf{C}$.

It was recommended that ZESCO, the national power company, should continue with their generation expansion programme and that independent power producers should also continue to invest in new power plants. Electricity tariffs also required revision as the price at which power was being produced was currently much higher than the prevailing rates at which the power was being sold. This was making it difficult for developers to sign agreements with investors in the power sector.

\subsection{Information and Communication Technology}

This sector was sub-divided into five subs-sectors as it is a very diverse infrastructure category. Collapsing it into a single sector would also have severely distorted the findings.

\section{Fixed Telephone Network}

The overall assessed grade for fixed telephone infrastructure was D. The quality and performance of the infrastructure was determined to be poor. The poor quality and lack of timely replacements or upgrades from analogue telephone exchanges to digital systems had contributed to the substitution of fixed-line telephones with mobile cellular communications, leading to the trend of a steady decline in the number of fixed-lines available in both urban and rural areas of the country [14].

The fixed telephone network suffers from slow uptake of newer technologies; this may be because of diminished capital injection due to competing technologies on the market. It was recommended that stakeholders should look at other technologies that would make the fixed telephone more profitable. Areas such as Internet Protocol and the use of fibre optic could increase the usage of fixed line subsector. Re-organisation within the monopoly provider or the introduction of a competitor could also invigorate the sub-sector

\section{Mobile Network}

The overall assessed grade for mobile phone infrastructure was $\mathbf{D}$, implying that the performance and quality of this sub-sector was poor. Despite the mobile network growing exponentially, its growth in rural areas was being limited by poor infrastructure. Service providers faced numerous quality of service challenges. These included long average call set up time, high call drop rates, and billing challenges on both voice calls and data bundles. Upgrade programs of setting up communication base stations towers were in progress to address some of the challenges [14].

In order to provide mobile services in rural areas, a deliberate policy of setting up mobile communication towers in the under-served jurisdiction should be implemented by the Government. In addition, mobile network operators, though competing, should share infrastructure especially in the rural areas.

International Gateway, Internet Infrastructure, and Internet Service Provider (ISP) Networks

The overall assessed grade for Internet Service Provider (ISP) network infrastructure was D. The capacity of the infrastructure was very low. Operations were also significantly low with numerous quality of service challenges. There was also poor coverage in rural areas. 
Numerous upgrade programs, especially fiber networks, were in progress at the time of the study [14].

The traditional ISP suffers strong competition from the mobile internet providers. There is need to invest in other technologies and use of other niche products to keep most of the traditional ISP's afloat. Stakeholders need to Investment in improving the fibre infrastructure in the country.

\section{Satellite Network}

The overall grade assessed for Satellite infrastructure was C, implying that the quality and performance of the infrastructure was fair. Satellites are mostly used in the remote rural areas, as backup links or by large multinational corporations for re-gaining private networks. Their usage as the primary link for most commercial ISP has dwindled drastically in preference to fibre optics. With an ever increasing high bandwidth services demand on the market, satellite communication would be an expensive and capacity limiting technology to choose for a country like Zambia whose ICT infrastructure is in its infancy and coverage is still very low [14]. To meet the expected demand, satellite is definitely not the answer and will remain in the shadows. However, it is clear that Satellite technology is important and it is currently leasing capacity on commercial satellite operators to where terrestrial ICT infrastructure cannot reach.

\section{Postal Services}

Most post office buildings were in need of maintenance works to bring them to modern and customer-friendly status. Some post office buildings required major rehabilitation works, as they were dilapidated [14]. The performance and quality of this sub-sector was found to be fair and therefore the infrastructure grade was $\mathbf{C}$.

The Post office has ordinarily and traditionally been the base of a Postal Service Infrastructure system used for transporting letters and other tangible objects. In view of the technological advancements, the Zambia Postal Services Corporation (ZAMPOST) has had to reposition itself to support the delivery of efficient and reliable public services. It is recommended that ZAMPOST continue to deliver traditional mail but also endeavour to deliver other public services through the use of ICT. There is also need to increase the security and scanning of both letters and other packages to determine contents as a deterrent and precaution against terrorist attacks.

\subsection{Airports}

The overall national score for Zambian Airports was a grade of $\mathbf{D}$, since a number of critical interventions were required in terms of rehabilitation, funding and planning in order to improve the quality of aviation infrastructure. In particular, several domestic airports had unpaved runways. The condition of terminal buildings and facilities was poor at a number of domestic and international airports. Navigation systems, communication, and metrology equipment at most airports were poor [15].
The internal resources of Zambian airports are not enough to meet the maintenance and expansion of needed infrastructure. There is need for airports to improve their revenue collection through internal sources such as passenger service charges, ground handling, and air navigation charges.

\subsection{Rail Infrastructure}

Generally, the rail infrastructure was in poor condition and the overall national grade awarded was $\mathbf{D}$. Zambia's railway network was found to suffer from two main constraints: poor track maintenance in the case of Zambia Railways; and low availability of main line locomotives and wagons in the case of the Tanzania-Zambia Railway Authority (TAZARA) network. These problems faced by the two railway companies have resulted in considerably reduced service capacity and hence their present inability to attract more traffic [16]. The cost for rehabilitating and maintaining the railway system is generally much higher than that of the road transport system; therefore, it is necessary to implement best practices for future maintenance as this will ultimately reduce maintenance costs than would be the case if maintenance is continually deferred as in the previous years.

The performance of Zambia's rail system can only improve if resources are provided for the track and rolling stock. In the past, railway operations have been hampered by little investment to replace depreciated equipment and limited resources for maintenance and repairs. Support from the Zambian governments has been at a low level to keep services running, and not sufficient to halt the deterioration of the quality of services.

\section{Conclusions and Recommendations}

Infrastructure is the foundation on which any country's economic and social well-being depends [17]. In general, Zambia's infrastructure system was found to be failing to keep pace with the current and growing national needs. The release of Zambia's first infrastructure report card received wide media coverage and urged the Zambian government to pay particular attention and consistently invest in: a transport system that moves people and goods efficiently; generation and transmission systems that deliver reliable, low-cost power from a wide range of energy sources; efficient communication; and water and sanitation systems that drive industrial processes as well as the daily functions in homes.

It should be noted that other infrastructure categories such as those for health, education, and agriculture were not considered in the report card due to budgetary constraints. For a more comprehensive evaluation, it was recommended that these be included in the next infrastructure assessment. It was further recommended that the Report Card Infrastructure assessment be carried out every two (2) years. 


\section{Acknowledgement}

The authors graciously acknowledge the financial support provided by the Engineering Institution of Zambia for the work reported in this article.

\section{Appendix}

Table 1. Infrastructure grading system

\begin{tabular}{|c|c|c|c|}
\hline Grade & Interpretation & $\begin{array}{c}\text { Weighting } \\
\text { Factor }\end{array}$ & Condition description \\
\hline A & Very good & $90-100 \%$ & $\begin{array}{c}\text { Infrastructure is fit for present and future use in terms of infrastructure condition, } \\
\text { committed investment, regulatory regime and planning processes }\end{array}$ \\
\hline B & Good & $80-89 \%$ & $\begin{array}{c}\text { Minor rehabilitation required in one or more of the infrastructure condition, committed } \\
\text { investment, regulatory regime and planning processes to enable infrastructure to be fit } \\
\text { for its present and future use. }\end{array}$ \\
\hline C & Fair & $70-79 \%$ & $\begin{array}{c}\text { Major rehabilitation required in one or more of the infrastructure condition, committed } \\
\text { investment, regulatory regime and planning processes to enable infrastructure to be fit } \\
\text { for its present and future use }\end{array}$ \\
\hline D & Poor & $41-69 \%$ & $\begin{array}{c}\text { Critical rehabilitation required in one or more of the infrastructure condition, committed } \\
\text { investment, regulatory regime and planning processes to enable infrastructure to be fit } \\
\text { for its present and future use }\end{array}$ \\
\hline F & Very Poor & $40 \%$ and below & The infrastructure is totally inadequate for present and future use \\
\hline
\end{tabular}

Source: EIZ (2012). Infrastructure Report Card (IRC) Framework

Table 3. Assessment criteria for Roads

\begin{tabular}{|c|l|l|}
\hline $\begin{array}{c}\text { Fundamental } \\
\text { component }\end{array}$ & \multicolumn{1}{|c|}{ Category description } & \multicolumn{1}{c|}{ Performance indicator } \\
\hline \multirow{2}{*}{ Condition } & Pavement condition & $\bullet \quad \begin{array}{l}\text { Surface age } \\
\text { Riding quality }\end{array}$ \\
\hline \multirow{4}{*}{ Capacity } & Load Carrying Capacity & $\bullet \quad$ Compare existing load capacity with current traffic volume \\
\cline { 2 - 4 } & Congestion & $\begin{array}{l}\text { Congestion levels at arterial intersections } \\
\text { Average travel time during peak hours } \\
\text { Average travel speed during peak hours }\end{array}$ \\
\hline \multirow{3}{*}{ Operations } & Safety & Auto and pedestrian fatalities particularly at intersections \\
\cline { 2 - 3 } & Customer satisfaction & Customer satisfaction surveys \\
\cline { 2 - 4 } & Funding & $\begin{array}{l}\text { Sufficiency of available funding for maintenance, rehabilitation and expansion of road } \\
\text { network }\end{array}$ \\
\hline Security & Physical & The susceptibility of the infrastructure to identifiable threats \\
\hline
\end{tabular}

Source: EIZ (2012). Infrastructure Report Card (IRC) Framework

Table 4. Assessment criteria for Rail

\begin{tabular}{|c|c|c|}
\hline $\begin{array}{c}\text { Fundamental } \\
\text { component }\end{array}$ & Category description & Criteria for grading \\
\hline \multirow{3}{*}{ Condition } & Track quality & Compliance of track to specified standards \\
\hline & $\begin{array}{l}\text { Communication and } \\
\text { signalling systems }\end{array}$ & $\begin{array}{ll}- & \text { Age of facilities } \\
\text { - } & \text { Physical condition of facilities }\end{array}$ \\
\hline & Rolling stock & - $\quad$ Age and condition of locomotives and trains \\
\hline Capacity & Track standard & The capacity, load and speed that the track can support \\
\hline \multirow{3}{*}{ Operations } & Passenger services & $\begin{array}{ll} & \text { Number of licensed passenger operators } \\
- & \text { Number of passengers annually } \\
- & \text { User satisfaction }\end{array}$ \\
\hline & Freight services & $\begin{array}{ll} & \text { Number of licensed freight operators } \\
\text { - } & \text { Volume of freight hauled compared to demand } \\
\text { - } & \text { User satisfaction } \\
\end{array}$ \\
\hline & Funding & Adequacy of funding for maintenance and renewal \\
\hline Security & Security system & $\begin{array}{l}\text { Adequacy of security systems to protect the track, bridges, signalling and power, control } \\
\text { systems and transport of hazardous cargo from identified threats }\end{array}$ \\
\hline
\end{tabular}


Table 5. Assessment criteria for Airports

\begin{tabular}{|c|c|c|}
\hline $\begin{array}{c}\text { Fundamental } \\
\text { component }\end{array}$ & Category description & Performance indicator \\
\hline \multirow[b]{2}{*}{ Condition } & Runway, apron and taxiway & $\begin{array}{l}\text { - } \quad \text { Pavement condition and residual life } \\
\text { - } \quad \text { Lighting }\end{array}$ \\
\hline & $\begin{array}{l}\text { Airport facilities: terminals, hangers, } \\
\text { lifts, communication and meteorology } \\
\text { systems etc }\end{array}$ & Age and physical condition \\
\hline \multirow{2}{*}{ Capacity } & Runway & Number and size of aircraft that can land and takeoff simultaneously \\
\hline & Airport facilities & Ability to accommodate aviation activities i.e. handling capability \\
\hline \multirow{3}{*}{ Operations } & Flight schedules & $\begin{array}{l}\text { - On time arrival time } \\
\text { On time departure time - to the extent that they are related to } \\
\text { infrastructure }\end{array}$ \\
\hline & Safety & Accidents and incidents involving aircraft \\
\hline & Funding & $\begin{array}{l}\text { Sufficiency of funding for maintenance and expansion of infrastructure to } \\
\text { match growth in aviation activity }\end{array}$ \\
\hline Security & Security system & $\begin{array}{l}\text { - } \quad \text { Ability to manage aviation security activity } \\
\text { - } \quad \text { Equipment and procedures to be used to maintain aviation security } \\
\text { - } \quad \text { How the airport will respond aviation security incidents }\end{array}$ \\
\hline
\end{tabular}

[9] Road Development Agency (RDA, 2014). Road Condition Report, December 2014.

\section{REFERENCES}

[1] The World Economic Forum (2014). Infrastructure Investment Policy Blueprint

[2] Development of an Infrastructure Report Card System for Zambia. The 53rd EIZ Annual General Meeting and Symposium Lusaka, Zambia 2009, pp 17-30

[3] Nickson Sing'andu (2009). An Assessment of the Impact of ZESCO's Power Rationing on Firm Productivity and Profitability: A Case of Selected Lusaka Based Manufacturing Firms.

[4] Chitonge, H. (2011). A Decade of Implementing Water Services Reform in Zambia: Review of Outcomes, Challenges and Opportunities

[5] Engineering Institution of Zambia (EIZ, 2015). 2014 Baseline Report Card for Zambia's Infrastructure

[6] Engineering Institution of Zambia (EIZ, 2012). Infrastructure Report Card Framework

[7] Nick Larson (2012). Infrastructure Report Cards - A Comparison of Canadian and International Experiences

[8] Engineering Institution of Zambia (EIZ, 2015). Zambia's 2014 Infrastructure Scorecard
[10] Rankin Engineering Consultants (2011). Inventory and Condition Survey of all Bridges and Major Culverts on the Core Road Network.

[11] Ministry of Local Government and Housing, Lusaka, Zambia (2012). The National Water Supply and Sanitation Steering Committee Report.

[12] Government of the Republic of Zambia, 2011. The National Urban Water Supply and Sanitation Programme, Ministry of Local Government and Housing, Lusaka, Zambia.

[13] ZESCO Limited. Annual Report 2011 - 2012.

[14] Zambia Information and Communications Technology Authority (ZICTA) (2014). Information and Communication Technology Sector Report July - September 2014, Lusaka, Zambia.

[15] Committee on Communications, Transport, Works and Supply (2012). Report for the Second Session of the Eleventh National Assembly Appointed on 26th September 2012.

[16] Africa Infrastructure Country Diagnostic (AICD) (2011). Zambia's Infrastructure: A Continental Perspective, Country Report.

[17] World Bank (2015). Transformation Through Infrastructure. World Bank, Washington, DC, USA. 